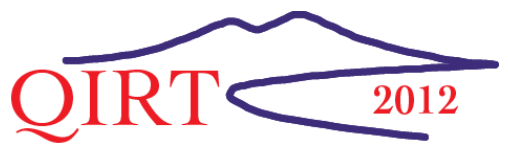

\title{
Campi Flegrei volcanic surveillance by thermal IR continuous monitoring
}

\author{
by F. Sansivero*, G. Vilardo*, P. De Martino*, V. Augusti* and G. Chiodini* \\ * Istituto Nazionale di Geofisica e Vulcanologia - Osservatorio Vesuviano, Via Diocleziano 238 - 80124 Napoli, \\ Italy, fabio.sansivero@ov.ingv.it
}

\section{Abstract}

Solfatara and Pisciarelli areas are the most impressive example of hydrothermal activity at Campi Flegrei caldera (Southern Italy). In these areas INGV-Osservatorio Vesuviano has been handling since 2004 a surveillance network for continuous, long-term volcanological monitoring of fumaroles fields by using thermal IR acquisition stations. In this paper different methodologies of analysis applied to time series of IR scenes are introduced and discussed. In spite of substantially different approaches to data analysis, the results of these methodologies agree with ground deformation data of the same area and likely are a useful tool for volcano monitoring and long-term risk definition.

\section{Introduction}

Among the several latest remote sensing techniques for volcano monitoring, ground-based thermal image data collection have demonstrated to be particularly useful to investigate quick processes associated to volcanic eruptions such as: lava flow fields evolution, lava dome activities, morphological variations at vents, opening of eruptive fissures, crater floor collapses, and pyroclastic flow deposit emplacement and cooling [1].

Applications of infrared thermal cameras in combination with geophysical and geochemical data have also demonstrated as qualitative and quantitative use of thermal images is essential for short-term surveillance giving quick information for hazard assessment [1].

In this paper equipment, techniques and methodologies used for continuous IR image data recording by permanent stations at Campi Flegrei Caldera (Naples, Italy) will be described, since these data have proved to be valuable for understanding volcanic processes related to quiescent volcanoes with hot fluid emission from diffuse degassing structures (DDSs, [2]).

\section{Short geological outline}

Solfatara is a volcanic vent inside the active caldera of Campi Flegrei, close to the city of Naples (Southern Italy, figure 1). Campi Flegrei nested caldera [3] is the product of two main caldera-forming eruptions:

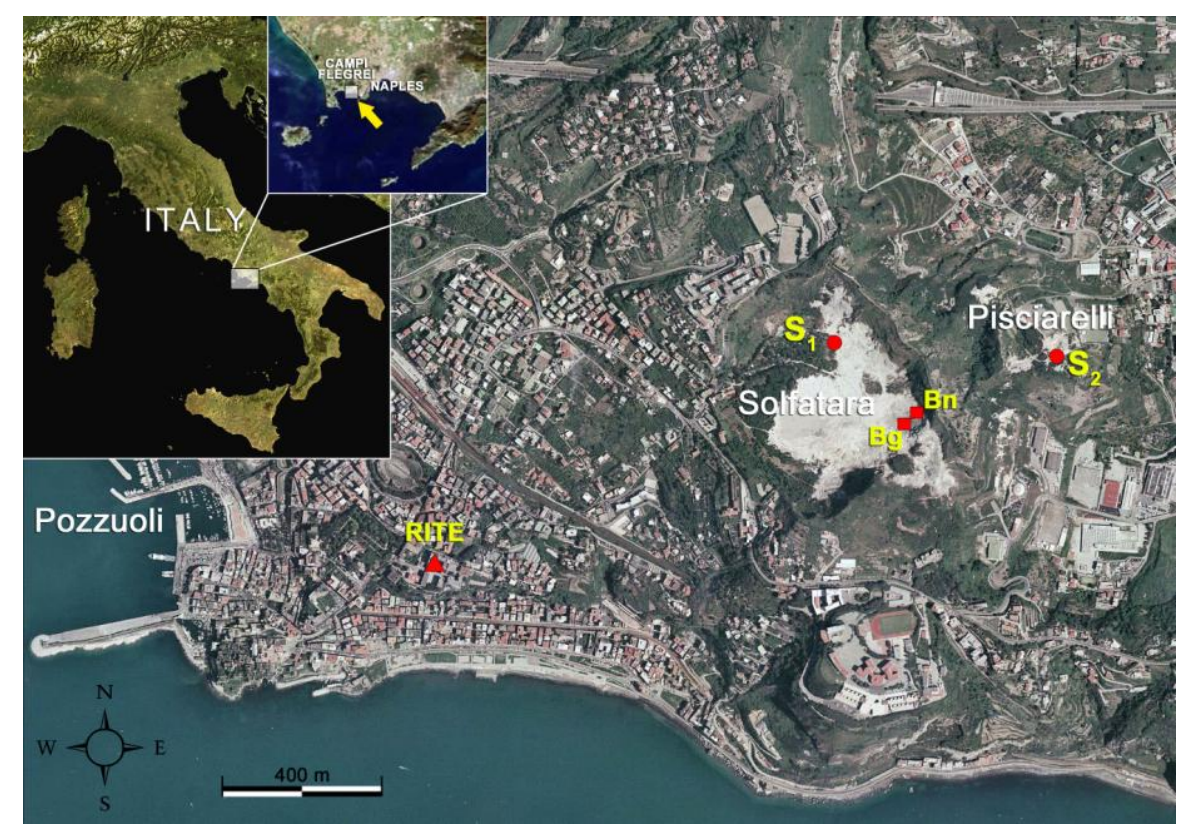

Fig. 1. Locations of Solfatara (S1) and Pisciarelli (S2) IR stations. RITE = GPS station at Rione Terra; $B g=$ Bocca Grande fumarole; $B n=$ Bocca Nuova fumarole 
The Campanian Ignimbrite $(\mathrm{Cl}, 39 \mathrm{kyr})$ and the Neapolitan Yelllow Tuff (NYT, $15 \mathrm{kyr}$ ) eruptions [4]. After NYT eruption intracaldera volcanism [5] lasted until the most recent eruption of Monte Nuovo (1,538 AD). The Campi Flegrei Caldera is interested by historical episode of slow ground deformations (called bradyseism) in its central part, nearby the town of Pozzuoli, due mainly to variations of the fluid pressure in the geothermal system [6]. In the last six years, the same area is characterized by an uplift of about $2 \mathrm{~cm} / \mathrm{yr}$.

Solfatara tuff-cone took place with a low-magnitude eruption occurred between 4.1 and $3.8 \mathrm{kyr}$ [5] ad it is made mainly of pyroclastic current deposits, phreatomagmatic coarse breccias and subordinately fallout pumice deposits. The morphology of Solfatara crater is controlled by NW-SE and SW-NE trending faults whose junction is the place of the most impressive example of hydrothermal activity at Campi Flegrei. Fumaroles at Solfatara have been reported since Greek times and actually the main emissions are in the crater (Bocca Grande and Bocca Nuova, figure 1) and on the base of the outer NE flank of the edifice (Pisciarelli locality, figure 1).

The thermal energy released by Solfatara (about $100 \mathrm{MW} /$ day; Chiodini et al., 2001a) and the flux of deeply derived fluids (about 5000 ton d-1; [7]) make this volcano one of the largest fumaroles fields of the world.

Several geochemical models of Campi Flegrei geothermal system have been proposed [2, 7, 8, 9]. The most recent geochemical conceptual model of Solfatara ([7]; figure 2) suggests a deep zone at 2000-2500 $\mathrm{m}$ where $\mathrm{CO}_{2}$-rich magmatic fluids, and isotopically mix with hydrothermal liquids similar to local meteoric waters at estimated temperatures of about $360^{\circ} \mathrm{C}$ (close to the critical point of pure water). As the hypocenters locations of seismic swarms is at the same depth of the mix zone, the model suggests that the origin of part of seismicity at Solfatara is due to fluids close to criticalsupercritical transition. Above the mix depth hydrothermal condition dominate and magmatic species disappear, below the mixing zone magmatic conditions prevail. Numerical simulations predicts a central zone, above the mix zone, in which fluids flows essentially as gas phase from an high-temperature area (about $360^{\circ} \mathrm{C}$ ) to a shallow area at temperatures from 190 to $230^{\circ} \mathrm{C}$ (spgz - single phase gas zone, figure 2).

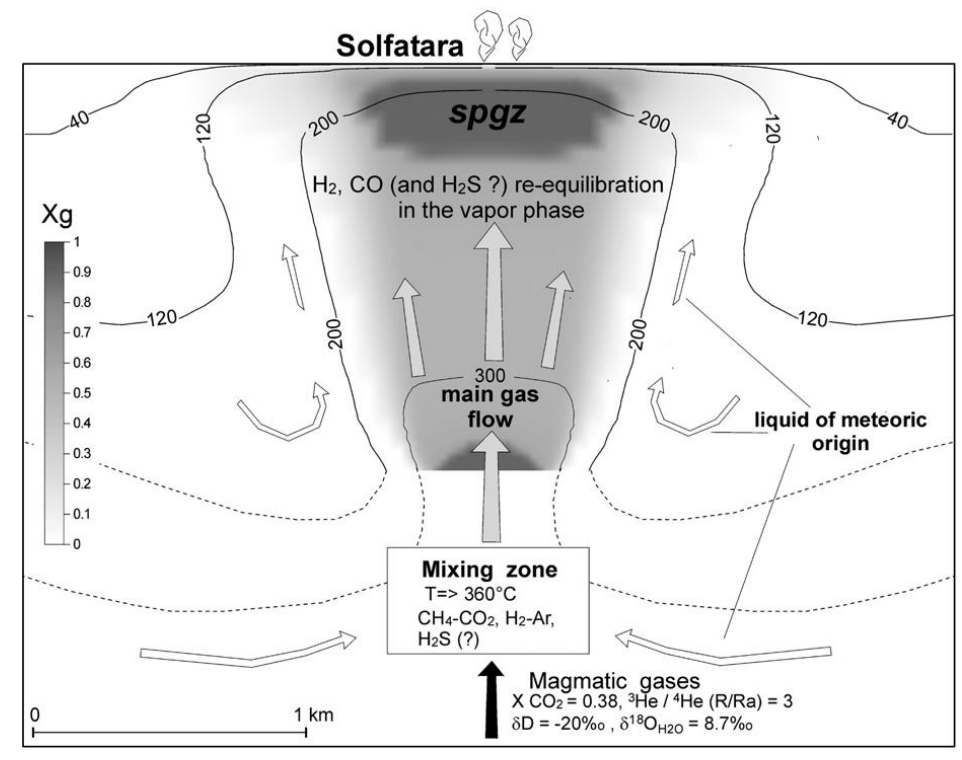

Fig. 2. Geochemical conceptual model of Solfatara according to [7].

The model suggests also a correlation between $\mathrm{CO}_{2} / \mathrm{H}_{2} \mathrm{O}$ ratio and mixing between magmatic and hydrothermal components; an increase of $\mathrm{CO}_{2} / \mathrm{H}_{2} \mathrm{O}$ ratio corresponds to high flux of the magmatic component and consequently a pressurization of the hydrothermal plume which generally is associated to higher surface and fumaroles temperatures and ground uplift. As validation of proposed model, in the last 30 years there has been a close correspondence between peeks of $\mathrm{CO}_{2} / \mathrm{H}_{2} \mathrm{O}$ ratio and ground deformations (occurred in the years 1985, 1990, 1995, 2007, 2011).

\section{The TIIMnet stations in the Campi Flegrei caldera}

The Thermal Infrared Imagery Monitoring Network (TIIMNet) is a surveillance network set up by INGVOsservatorio Vesuviano, composed of IR acquisition stations planned for continuous, long-term volcanological monitoring of fumaroles fields in the Neapolitan volcanic areas. The stations in the Campi Flegrei caldera are located inside the Solfatara crater and at Pisciarelli (figure 1; [10]) and are equipped with NEC Thermo Tracer TS7302 IR cameras, with focal plane array (FPA) uncooled microbolometer (320x240 pixel).

At Solfatara the station is operative since July $2004[10,11]$ and it represents one of the first long-term IR monitoring system inside a degassing volcanic crater on earth. The station acquires scenes of the SE inner slope of Solfatara (figure $3 \mathrm{a}$ ) at the intersection of two active, SW-NE and NW-SE main faults where the major fumaroles are located at an average distance of about $300 \mathrm{~m}$ from the IR camera. 
The station at Pisciarelli, operative since October 2006, acquires scenes of the outer eastern flank of the Solfatara tuff-cone (average distance of fumaroles is about $130 \mathrm{~m}$ ), corresponding to an area characterized by heavy water vapor and $\mathrm{CO}_{2}$ emissions (figure $3 \mathrm{~b}$ ).

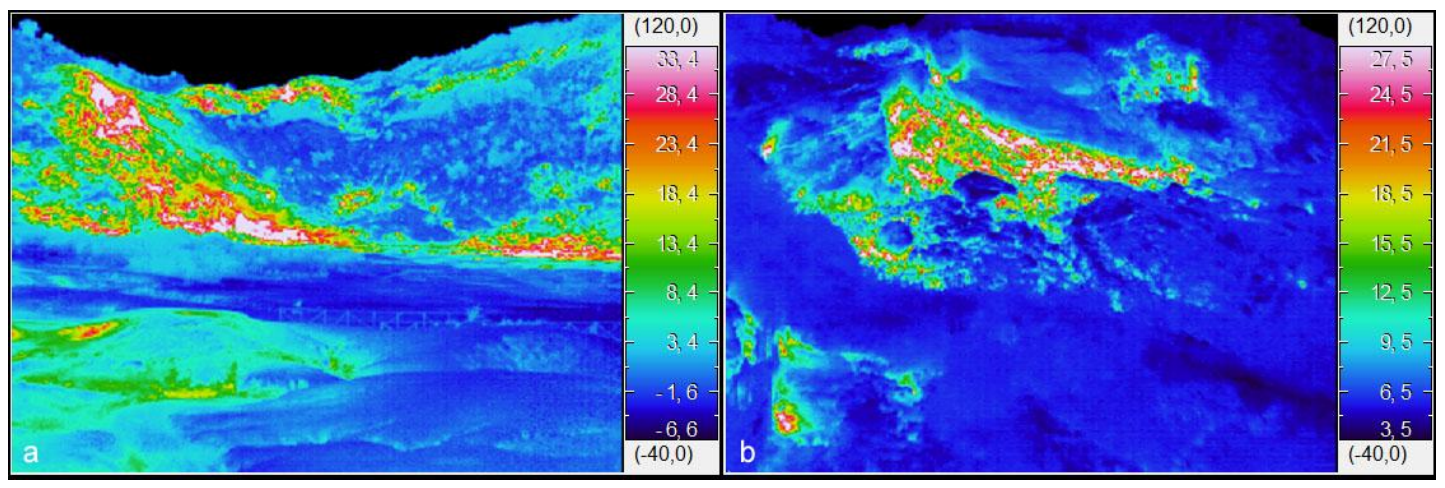

Fig. 3. Thermal infrared images from Solfatara (a) and Pisciarelli (b) stations.

Both IR cameras are inside a protective stainless steel housing, resistant to corrosive elements and with a shooting window of germanium glass, transparent to the thermal wavelengths; the cameras are connected to the Remote Monitoring Stations (RMS) which controls the shooting functionalities of IR sensors and the connection to the surveillance Centre. The Control Unit, located at the surveillance Center of INGV-Osservatorio Vesuviano in Naples, communicates with the RMS through GSM frequency network and it allows to configure times and shooting parameters and to run the automatic uploading of the remotely acquired thermal images.

Infrared images, belonging to LWIR (Long-Wavelength InfraRed) spectrum, are acquired daily at three different times during the night.

\section{Time series analyses}

In order to obtain accurate temperature values representative of surface temperatures of fumaroles fields, different processing methodologies were applied to time series of IR scenes obtained from the stations of Solfatara and Pisciarelli. The corrections aim is to adjust most of the influences related to external factors (e.g. emissivity and surface roughness of target, viewing angle, atmospheric effects, path length, presence of volcanic gas, etc) on the radiation detected by the thermal camera [11].

First, it was performed the in-situ calibration of IR image temperatures by using a $\mathrm{K}$ type thermocouple on the field. The comparison shown the same time pattern with an excellent correlation (R2=0.989) for the two sets of temperatures, suggesting not to apply any correction to the rough data and to analyze time series of IR temperatures in terms of relative temperature variations [10].

As second step, it has been taken in account the quality (i.e. sharpness, contrast, brightness, etc.) of the IR scene excluded sky (SES). As the clearest images had highest SD values while the blurred, low-quality images were characterized by lowest SD values [11], the Standard Deviation (SD) of IR images was chosen as a good indicator of quality. Generally lowest SD values meant rainfall during image acquisition, on the other hand, too high SD values denoted scattering of IR temperature values due to enhanced air IR absorption caused by fog or the presence of a larger plume of condensed steam in the fumaroles field $[12,13]$. According to this significance of Standard Deviation, IR images whose SD values were outside the $2 \mathbf{s}$ interval, as defined by Gaussian fit (figure 4), were not selected for time series analyses.
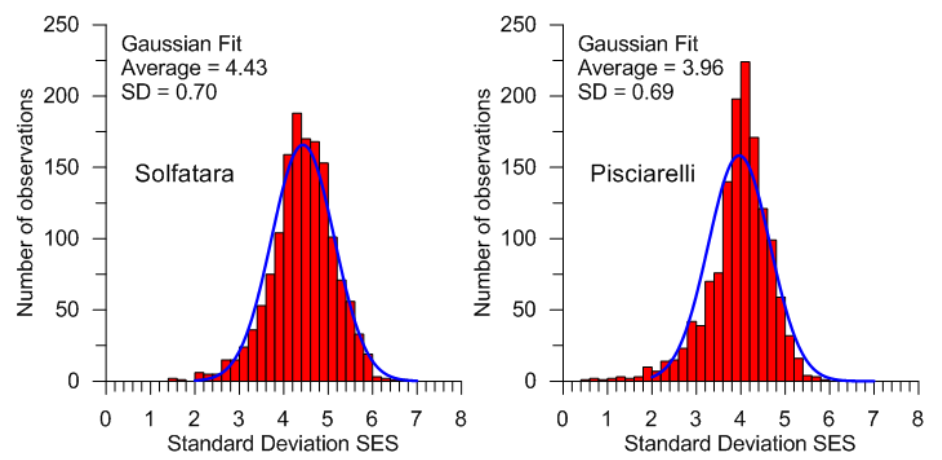

Fig. 4. Frequency distribution of the Standard Deviation of the pixel temperature of the scene excluded sky (SES) 
In order to better analyze the influence of environmental parameters, IR mean temperatures were correlated to dataset of meteorological data [11]. Correlations shown as air mean temperature had a very good correlation coefficient $(r=0.98)$ with the mean temperature of the SES; wind speed and pressure had a moderate correlation $(r=-0.17$ and $r=-$ $0.19)$ and relative humidity had no considerable correlation. In addiction the results of a multi parametric regression analysis showed that about $96 \%$ of IR mean temperature variance is explained by air temperature [11]. The efficient seasonal control on the IR temperatures at the surface is clearly observed in the chronograms of the maximum temperature values of the SES at both Solfatara and Pisciarelli (figure $5 a, b$ ).
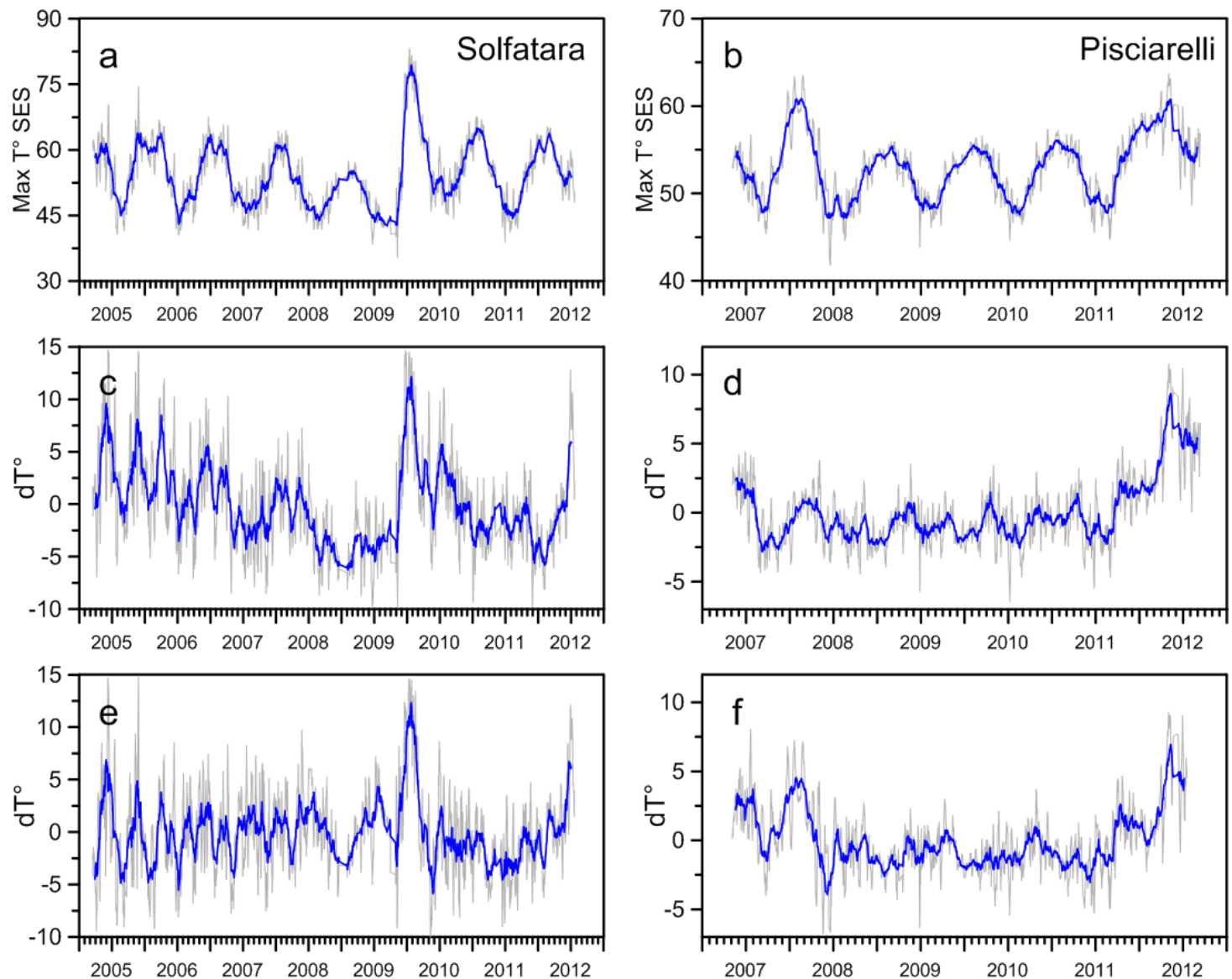

Fig. 5. Chronograms of the maximum IR temperature of the whole scene excluded sky (SES). a) Solfatara row data; b) Pisciarelli row data; $c$ ) Solfatara temperature residuals after background correction; d) Pisciarelli temperature residuals after background correction; e) Solfatara temperature residuals after seasonal cyclicity removal; f) Pisciarelli temperature residuals after seasonal cyclicity removal. Grey line = weekly moving average. Blue line = monthly moving average.

This observations suggested to subtract mean IR temperature values of a background area from IR temperature values of all the pixels of the IR scene as simple starting filtering approach which reduced significantly the effect of environmental parameters on temperature values of the scene. Nevertheless time series continued to exhibit secondary, well detectable, seasonal patterns due to the annual temperature cycle. Better results were reached by performing a background correction of the temperature values based on the high linear correlation observed between the maximum temperatures of SES ( $\left.T_{S E S}\right)$ and the maximum temperatures of a background area $\left(T_{B K G}\right)$ identified in the IR image as not affected by thermal anomaly.

On the basis of the parameters of the line that best fit the data a background correction has been applied to the time series of the maximum temperature values on the basis of the following equation:

$$
d T=T_{S E S}-T_{L F}
$$

where $d T$ is the temperature residual and $T_{L F}$ represents the expected maximum temperature value of SES estimated on the basis of the coefficients of the linear fit between $T_{S E S}$ and $T_{B K G}$. respectively.

In figure $5 c$ and $5 d$ are shown the time series of the temperature residuals $(d T)$ for Solfatara and Pisciarelli 
A different methodology used to process the temperature data which show temporal pattern with seasonal cyclicities (figure $5 \mathrm{a}, \mathrm{b}$ ), involved a filtering procedure consisting in the periodicities removal by using a MatLab tool (TSView, part of Gamit/Globk MatLab Tools), which finds statistically significant periodicities in time series and remove the related harmonics.

The Solfatara and Pisciarelli time series show only a statistically significant yearly harmonic which has been removed by the software tool. By this way the temperature trend is cleared by influence of endogenous cyclical factors and possible temperatures anomalies seems to be better evidenced. Plots of the filtered time series are shown in figures $5 e$ and $f$.

With the aim of identifying further thermal parameters useful to describe the variation in time of the thermal anomalies, both in terms of their extent and temperature values, another approach has been recently attempted by developing a software (IRAnalyst) which determines maximum temperature values of a selected area in the IR scene and displays them by marking the pixel for every scene of the time series. Then it calculates the mean temperature of a $\mathrm{n}$ pixel buffer (MBT) centered on the selected maximum value for each IR scene (figure 6). The software performs also a Standard Deviation filtering and the background correction by applying equation (1). The results of this analysis give both information about distribution of temperature anomalies in the IR scenes and variations of MBT values vs time, which can be in turn filtered by TSView tool.

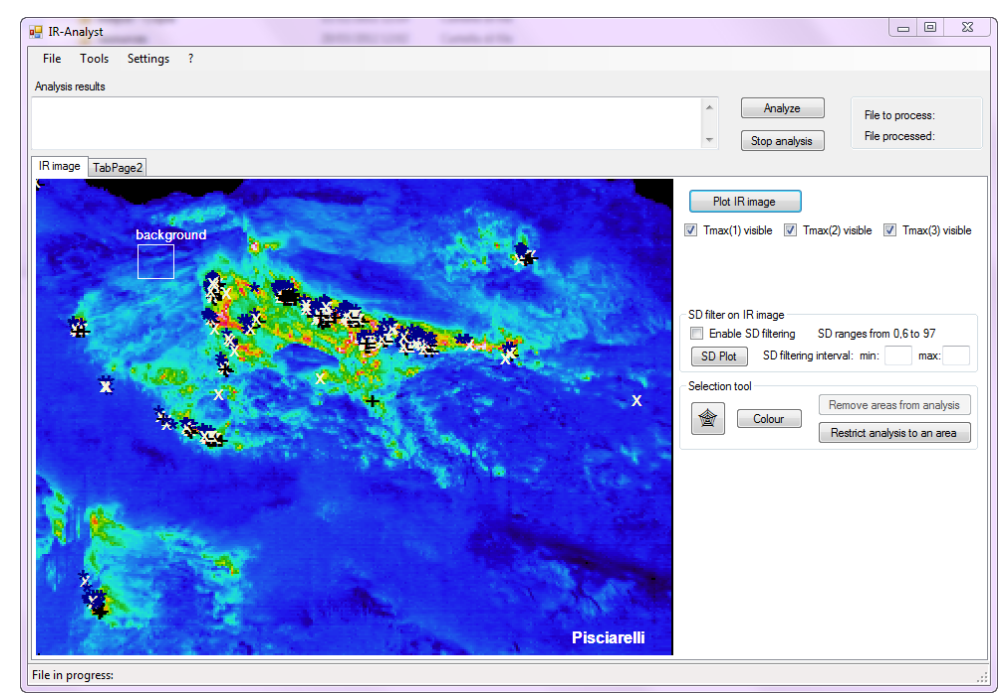

Fig. 6. Screenshot of IRAnalyst software. Background IR figure is from Pisciarelli station.

A further methodology applied to the time series of the IR image dataset consists of a pixel by pixel regression of temperature residuals $(d T)$ with respect to time in order to investigate local temperature changes of the scene [11]. Since this methodology requires an accurate correlation between the pixels of different IR images, the first step of the procedure involves the co-registration of each image of the whole dataset by cross-correlation analysis to a reference scene, The results of the regression have been mapped and they evidenced the presence of some areas characterized by temperature increases and other areas which are being cooled (figure 7 ).

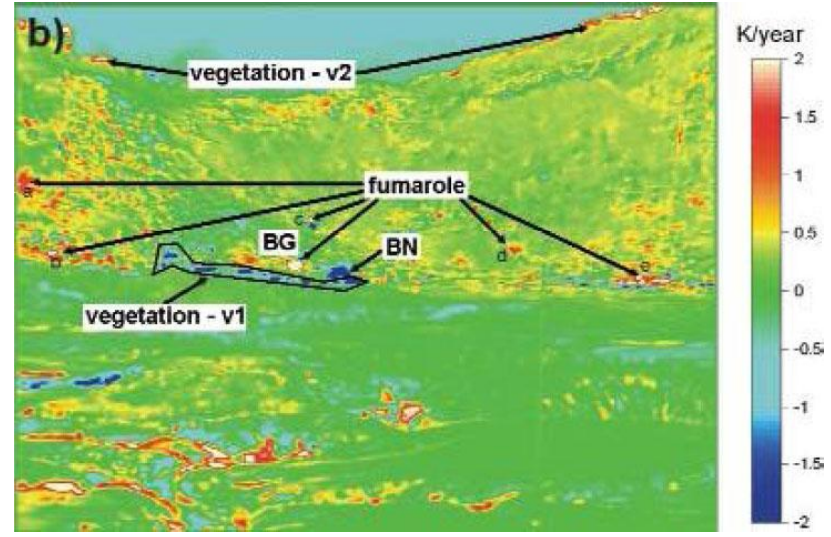

Fig. 7. Map of the pixel by pixel regression of IR temperature residuals according to [11]. 
The observed temperature increase regarded the nearby hot areas probably affected by an increased fumarole fluids flux. On the contrary, the temperature decreases are not linked to the variation of the hydrothermal source but they reflect the anthropic jobs or vegetation growth [10, 11].

It is noteworthy as all the analysis procedures previously described are based on information contained in the image itself, making these procedures independent from the availability of external data.

\section{Results from time series analysis}

In figure 8 the time series of IR data from Pisciarelli, processed with TSView Matlab tool, and the time series of GPS elevation data from RITE station (figure 1) are shown. The data show strong correlations between IR temperatures trend and ground deformations trend from GPS data. In particular: a) in the year 2007, after an intense fumarole degassing occurred during the 2006 at Pisciarelli [14], both temperature and ground deformations show long period oscillations of moderate amplitude; b) from 2008 to the beginning of 2011 ground deformation shows a moderate uplift (about $1.3 \mathrm{~cm} / \mathrm{yr}$ ) whereas temperature does not show significant variations; c) from spring 2011 ground deformation shows an appreciable increase of the uplift velocity clearly correlated with a marked increase of IR temperatures.

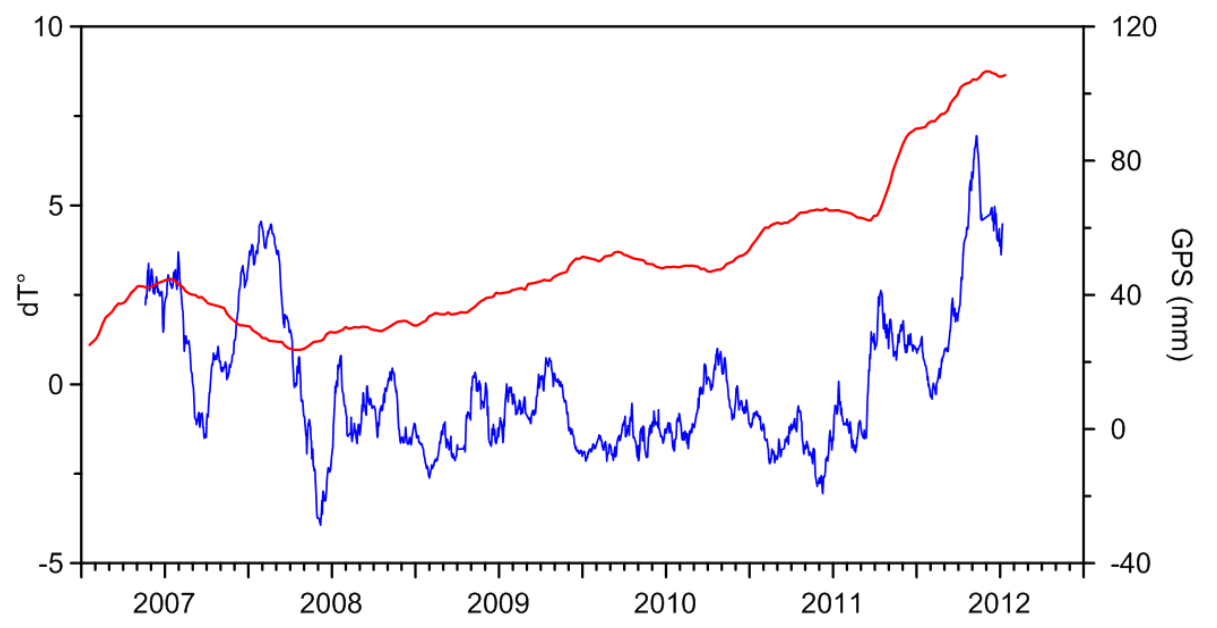

Fig. 8. Time series of temperature residuals, processed with TSView tool, from Pisciarelli station (blue line) and GPS elevation data from RITE station (red line).

These evidences at Pisciarelli site are a starting point to better understand the relationships between surface temperatures fields, hydrothermal system and ground deformations.

Data from Solfatara station are more difficult to process than Pisciarelli ones, due to a multiplicity of elements:

- high distance between IR camera and studied scene (300 m):

- Bocca Grande (figure 1) fumarole plume, causes interference on the IR scene as it covers different parts of scene depending from wind direction;

- ground deformation of the station site produce a tilt of IR camera and consequently a displacement of the IR scene;

- slow migration of the position of some fumaroles to hidden positions for the IR camera could be interpreted as a slow cooling of this area.

- anthropic jobs and vegetation growth strongly affect the scene.

For the exposed reasons data processing of IR images from Solfatara station analysis is still in progress.

\section{Conclusions}

The different methodologies described before provided results of thermal IR images analysis which give a detailed picture of the evolution of surface temperatures in high degassing areas of the Campi Flegrei caldera.

As it is well known, low dynamics quiescent volcanoes can release large amount of energy by diffuse degassing occurring in restricted areas commonly associated to regions of high permeability (faults, fractures). The energy dissipated by hydrothermal and volcanic gaseous emissions is an important component of the energy balance of the volcanic system $[11,15]$, so continuous acquisition of thermal IR data can provide useful information about temperature changes, opening/closure of fumaroles and their migration, which in turns provide insights into the subsurface processes occurring in magmatic and hydrothermal systems. The results of IR time series analysis confirm continuous thermal infrared image acquisition as a useful tool for volcano monitoring and long-term risk definition. 


\section{REFERENCES}

[1] Spampinato L., Calvari S., Oppenheimer C., Boschi E., "Volcano surveillance using infrared cameras". EarthScience Reviews 106, 63-91, 2011.

[2] Chiodini, G., F. Frondini, C. Cardellini, D. Granieri, L. Marini, and G. Ventura, "CO2 degassing and energy release at Solfatara Volcano, Campi Flegrei, Italy". J. Geophys. Res., 106, 16,213-216,221, 2001.

[3] Orsi, G., De Vita, S. \& Di Vito, M., "The restless resurgent Campi Flegrei caldera (Italy): constraints on its evolution and configuration", J. Volc. Geotherm. Res., 74, 179-214, 1996.

[4] Deino A. L.; Orsi G., de Vita S., Piochi M., "The age of the Neapolitan Yellow Tuff caldera-forming eruption (Campi Flegrei caldera - Italy) assessed by ${ }^{40} \mathrm{Ar} /{ }^{39} \mathrm{Ar}$ dating method”. J. Volc. Geotherm. Res. 133, 157-170, 2004.

[5] Di Vito, M., Isaia, R., Orsi, G., Southon, J., de Vita, S., D’Antonio, M., Pappalardo, L. \& Piochi, M., "Volcanism and deformation since 12.000 years at the Campi Flegrei caldera (Italy)". J. Volc. Geotherm. Res. 91, 221-246, 1999.

[6] Chiodini G., Todesco M., Caliro S., Del Gaudio C., Macedonio G., and Russo M., "Magma degassing as a trigger of bradyseismic events; the case of Phlegrean Fields (Italy)". Geophys. Res. Lett. 30(8), 1434. doi:10.1029/2002GL01679, 2003.

[7] Caliro S., Chiodini G., Moretti R., Avino R., Granieri D., Russo M., Fiebig J., "The origin of the fumaroles of La Solfatara (Campi Flegrei, South Italy)". Geoch. et Cosmoch. Acta 71, 3040-3055, 2007.

[8] Chiodini G., and Marini L., "Hydrothermal gas equilibria; the $\mathrm{H} 2 \mathrm{O}-\mathrm{H} 2-\mathrm{CO} 2-\mathrm{CO}-\mathrm{CH} 4$ system". Geochim. Cosmochim. Acta, 62(15), 2673-2687, 1998.

[9] Chiodini G., Cioni R., Guidi M., Magro G., Marini L., Panichi C., Raco B., and Russo M., "Vesuvius and Phlegrean Fields; Gas geochemistry; Geochemical monitoring of the Phlegrean Fields and Vesuvius (Italy) in 1996". Acta Vulcanol. 12(1-2), 117-119, 2000a.

[10] Vilardo G., Chiodini G., Augusti V., Granieri D., Caliro S., Minopoli C.and C. Terranova, "The permanent thermal infrared network for the monitoring of hydrothermal activity at the Solfatara and Vesuvius volcanoes". In: "Conception, verification, and application of innovative techniques to study active volcanoes" Marzocchi W. and A. Zollo (Editors), INGV, ISBN 978-88-89972-09-0, 483-495, 2008.

[11] Chiodini, G., Vilardo, G., Augusti, V., Granieri, D., Caliro, S., Minopoli, C., Terranova, C.,"Thermal monitoring of hydrothermal activity by permanent infrared automatic stations: results obtained at Solfatara di Pozzuoli, Campi Flegri (Italy)". J. Geophys. Res. 112, B12206, 2007.

[12] Furukawa Y., "Infrared thermography of the fumarole area in the active crater of the Aso volcano, Japan, using a consumer digital camera". J. of Asian Earth Sciences 38, 283-288, 2010.

[13] Sawyer, G.M., Burton, M.R., "Effects of a volcanic plume on thermal imaging data". Geophys. Res. Lett. 33, L14311, 2006.

[14] Chiodini, G., Caliro, S., Cardellini, C., Granieri, D., Avino, R., Baldini, A., Donnini, M. and C. Minopoli "Long-term variations of the Campi Flegrei, Italy, volcanic system as revealed by the monitoring of hydrothermal activity". J. Geophys. Res. 115, B03205, doi:10.1029/2008JB006258, 2010.

[15] Chiodini G., Granieri D., Avino R., Caliro S., Costa A., and Werner C., "Carbon dioxide diffuse degassing and estimation of heat release from volcanic and hydrothermal systems". J. Geophys. Res., 110. doi:10.1029/2004JB00354, 2005. 